\title{
Gastroduodenal anastomotic insufficiency: pull-through technique for endoscopic negative pressure therapy with new types of open-pore drains
}

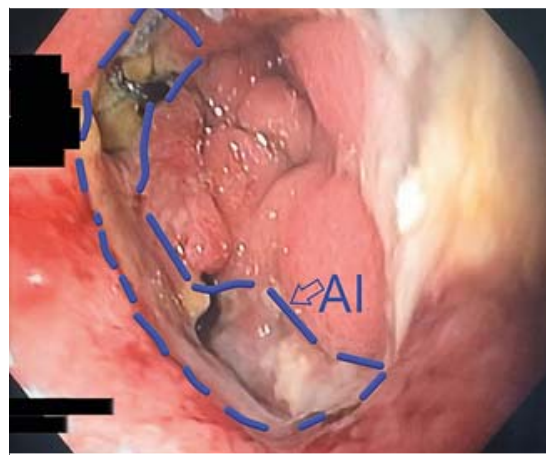

$\checkmark$ Fig. 1 Endoscopic diagnosis of semicircular anastomotic leakage (Al) 12 days after distal gastric resection and Billroth I operation.

A 61-year-old man underwent distal gastric resection with gastroduodenal anastomosis (Billroth I operation) because of perforated peptic ulcer and septic peritonitis. In addition, ischemic right colon was resected and ileostomy was performed. Anastomotic insufficiency was detected 2 days after the operation by duodenal secretions in the operative drainage tube. In two repeat laparotomies, operative closure of the leak could not be achieved. On postoperative Day 12, endoscopy showed a semicircular anastomotic leak ( $\triangleright$ Fig. 1 ). The drain could be seen through the defect from the inside. Endoscopic negative pressure therapy (ENPT) was initiated immediately.

We used two new types of drainage devices: open-pore polyurethane foam drainage (OPD) and open-pore film drainage (OFD) ( Fig. 2) [1 -4]. For construction, the distal ends of two drainage tubes were connected using a suture. The connecting segment was wrapped with open-pore polyurethane foam or coated with a strip of thin double-layered open-pore drainage film (Suprasorb CNP Drainagefolie; Lohmann \& Rauscher, Neuwied, Germany) ( $\triangleright$ Video 1 ). This open-pore element was placed using a

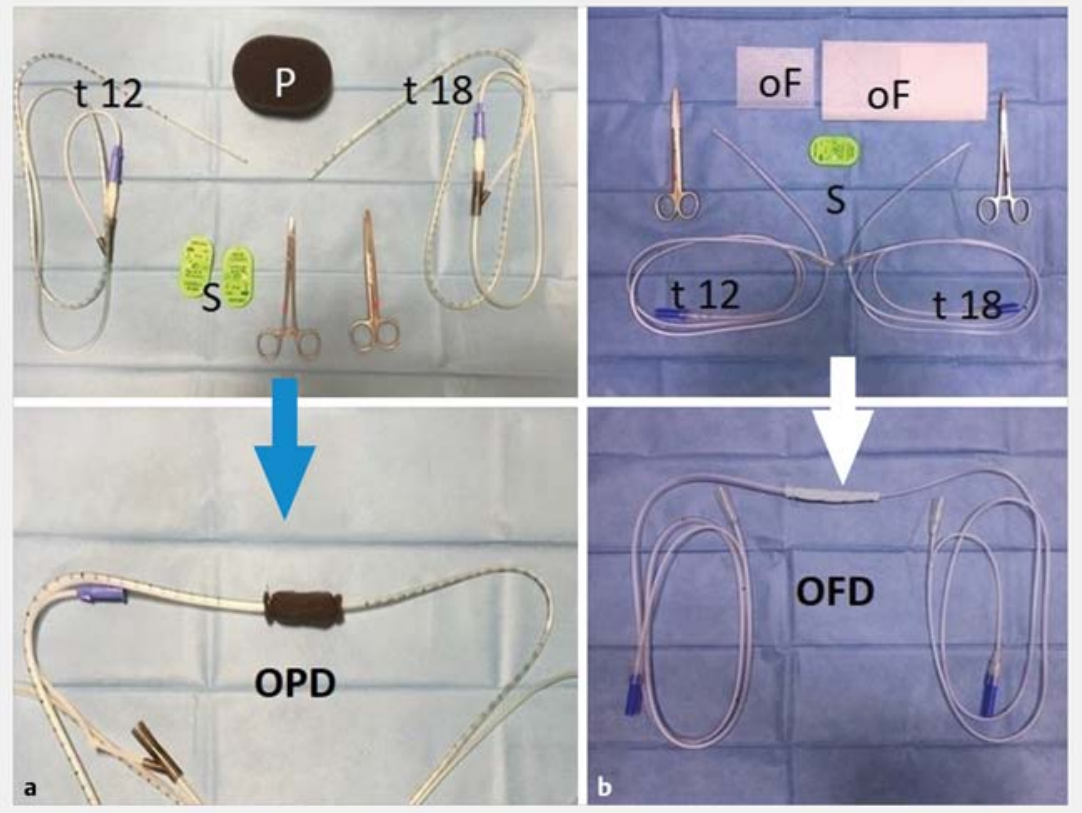

Fig. 2 Two types of pull-through drains. For construction, the distal ends of a $12 \mathrm{Fr}$ and an $18 \mathrm{Fr}$ drainage tube ( $\mathrm{t}$ ) were connected using a suture (S). a Open-pore polyurethane foam (P) was fixed in the middle for open-pore polyurethane foam drainage (OPD). $\mathbf{b}$ Thin open-pore film (oF) was fixed in the middle of the drain for open-pore film drainage (OFD).

\section{Pull-through technique with new types of open-pore drains}

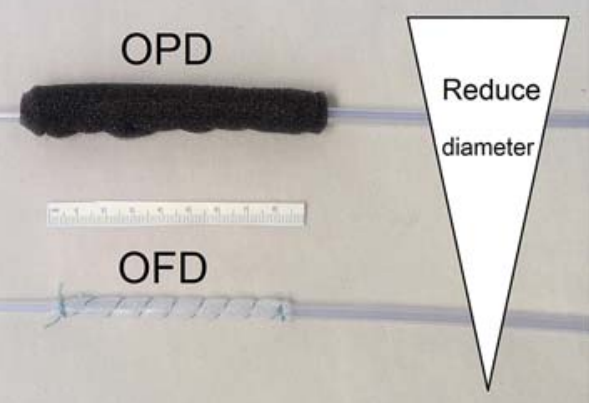

Video 1 Demonstration of the pull-through technique, construction of the open-pore polyurethane foam drain (OPD) and removal of an open-pore film drain (OFD). 


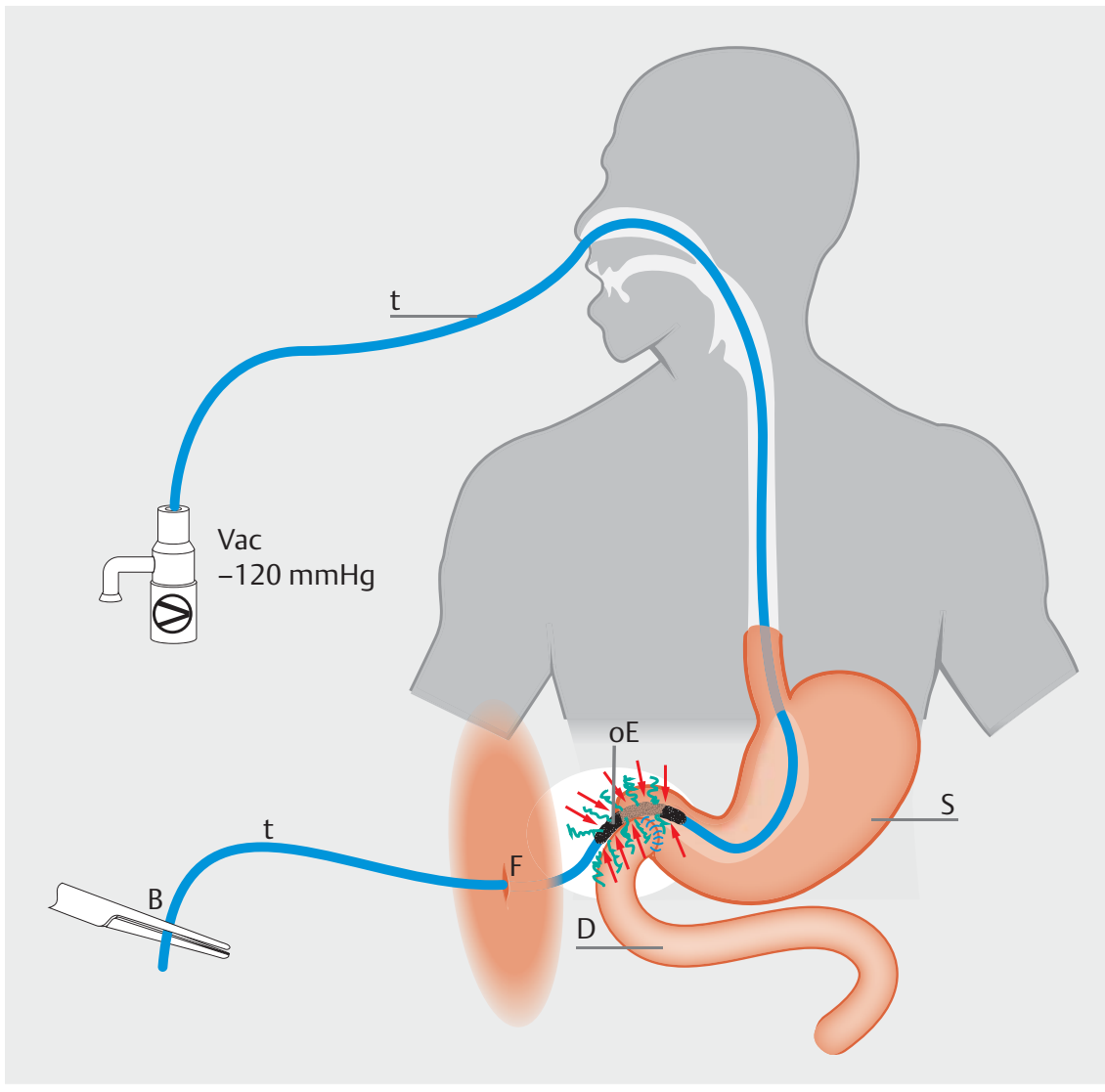

Fig. 3 Schema of endoscopic negative pressure therapy (ENPT) with pull-through technique. The open-pore element $(\mathrm{oE})$ was fixed in the middle part of a drainage tube $(\mathrm{t})$ and placed in the duodenal defect. The oral end of the tube was connected to an electronic vacuum device ( $\mathrm{Vac},-125 \mathrm{mmHg}$ ), and the cutaneous end of the tube was blocked (B). D, duodenum; S, stomach; F, cutaneous fistula opening.

pull-through technique ( $\triangleright$ Video 1$)$ along the preformed fistula channel in the anastomotic defect, with one half lying inside the cavity and the other half inside the intestinal lumen ( $\mathbf{F i g . 3}$ ). The correct position was controlled endoscopically. The cutaneous end of the tube was blocked with a knot, and the proximal end was led out through the nose and connected to an electronic vacuum pump (ActiV.A.C, setting: $-125 \mathrm{mmHg}$, continuous negative pressure, high intensity; $\mathrm{KCl}$, San Antonio, Texas, USA). We started ENPT with OPD and progressed to small-bore OFD. The changing interval was 3-5 days, and the diameter of the OPD and OFD drains was reduced in a stepwise fashion (from $15 \mathrm{~mm}$ to $5 \mathrm{~mm}$ ). The biliary secretion stopped immediately from the cutaneous end, and was

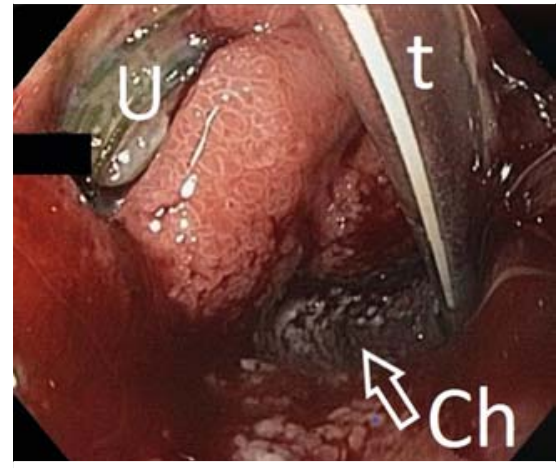

Fig. 4 Day 21 of endoscopic negative pressure therapy. The open-pore polyurethane foam drain has been pulled out of the defect channel (Ch). In the channel, an erosive pattern caused by the suction can be seen. $t$, tube; $U$, ulceration.

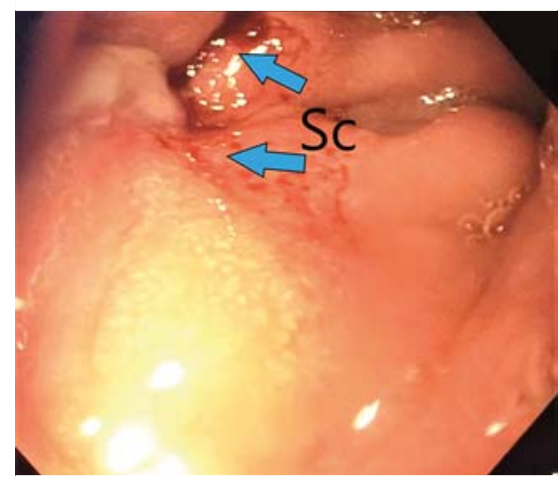

- Fig. 5 Complete healing of the defect at follow-up, 11 days after the end of endoscopic negative pressure therapy. Sc, scar.

The authors

drained intraluminally with negative pressure. Simultaneously, the defect and the fistula channel collapsed around the open-pore element of the drain ( Fig.4). The last period of ENPT was performed using OPD, which was placed intraluminally, completely covering the defect zone. Drains were changed six times. The duration of ENPT was 24 days. The defect healed without further operation ( $\mathbf{F i g} \mathbf{5}$ ).

Endoscopy_UCTN_Code_TTT_1AO_2AI

\section{Competing interests}

Dr. Loske is a consultant for Lohmann \& Rauscher GmbH \& Co.KG.
Frank Rucktaeschel ${ }^{1}$, Marc Liedtke ${ }^{2}$, Erik Schlöricke ${ }^{2}$, Thomas Herrmann ${ }^{3}$, Gunnar Loske ${ }^{3}$

1 Department for Internal Medicine, Gastroenterology, Hemato-Oncology, Nephrology and Endocrinology,

Westküstenklinikum Heide, Heide, Germany

2 Department for Abdominal, Thoracic and Vascular Surgery, Westküstenklinikum Heide, Heide, Germany

3 Department for General, Abdominal, Thoracic and Vascular Surgery, Katholisches Marienkrankenhaus Hamburg gGmbH, Hamburg, Germany 


\section{Gunnar Loske, MD}

Department for General, Abdominal, Thoracic and Vascular Surgery, Katholisches Marienkrankenhaus Hamburg gGmbH, Alfredstrasse 9, 22087 Hamburg, Germany Fax: +49-40-25461400

loske.chir@marienkrankenhaus.org

\section{References}

[1] Loske G, Liedke M, Schlöricke E et al. Endoscopic negative-pressure therapy for duodenal leakage using new open-pore film and polyurethane foam drains with the pullthrough technique. Endoscopy 2017; 49: E300-E302
[2] Fischer A, Thimme R, Hopt U et al. Two-sided sponge (TSS) treatment: description of a novel device and technique for endoscopic vacuum treatment (EVT) in the upper gastrointestinal tract. Endosc Int Open 2016; 4: E937-E940

[3] Loske G. Endoscopic negative pressure therapy of the upper gastrointestinal tract. Chirurg 2018. doi:10.1007/s00104-0180727-x

[4] Loske G, Müller CT. Tips and tricks for endoscopic negative pressure therapy. Chirurg 2018. doi:10.1007/s00104-018-0725-z

\section{Bibliography}

DOI https://doi.org/10.1055/a-0824-6130

Published online: 7.2.2019

Endoscopy 2019; 51: E85-E87

(c) Georg Thieme Verlag KG

Stuttgart · New York

ISSN 0013-726X
ENDOSCOPY E-VIDEOS

https:/|eref.thieme.de/e-videos

口回 Endoscopy E-Videos is a free access online section, reporting 田: on interesting cases and new techniques in gastroenterological endoscopy. All papers include a high quality video and all contributions are freely accessible online.

This section has its own submission website at https://mc.manuscriptcentral.com/e-videos 